REVIEW ARTICLE OPEN

\title{
The metabolic flexibility of quiescent CSC: implications for chemotherapy resistance
}

\author{
Kangchen Chen ${ }^{1,2,3,5}$, Chenzhi Zhang ${ }^{2,3,4,5}$, Sunbin Ling ${ }^{1,2,3}$, Rongli Wei $i^{1,2,3,4}$, Jianguo Wang ${ }^{1,2,3}$ and Xiao Xu (D) ${ }^{1,2,3} \bowtie$
}

(c) The Author(s) 2021

Quiescence has been observed in stem cells (SCs), including adult SCs and cancer SCs (CSCs). Conventional chemotherapies mostly target proliferating cancer cells, while the quiescent state favors CSCs escape to chemotherapeutic drugs, leaving risks for tumor recurrence or metastasis. The tumor microenvironment (TME) provides various signals that maintain resident quiescent CSCs, protect them from immune surveillance, and facilitates their recurrence potential. Since the TME has the potential to support and initiate stem cell-like programs in cancer cells, targeting the TME components may prove to be a powerful modality for the treatment of chemotherapy resistance. In addition, an increasing number of studies have discovered that CSCs exhibit the potential of metabolic flexibility when metabolic substrates are limited, and display increased robustness in response to stress. Accompanied by chemotherapy that targets proliferative cancer cells, treatments that modulate CSC quiescence through the regulation of metabolic pathways also show promise. In this review, we focus on the roles of metabolic flexibility and the TME on CSCs quiescence and further discuss potential treatments of targeting CSCs and the TME to limit chemotherapy resistance.

Cell Death and Disease (2021)12:835; https://doi.org/10.1038/s41419-021-04116-6

\section{FACTS}

Cancer stem cells (CSCs) are identified in most types of liquid and solid tumors and contribute to tumor onset, chemotherapy resistance, recurrence, and metastasis.

When the bulk of the tumor cells are eliminated by adjuvant treatments, CSCs may survive in a reversible quiescent state. In both adult stem cells and CSCs, low ROS levels are frequently associated with a protective intracellular environment and with the perseverance of stem cell quiescence/ dormancy.

CSCs can reprogram their metabolism to flexibly adapt to environmental changes, which is considered critical for them to enhance the antioxidant compensative capacity and sustain their self-renewal ability.

\section{OPEN QUESTIONS}

What gives rise to the emergence of quiescent CSCs?

What kind of metabolic flexibility favors the maintenance of quiescent CSCs?

Which are the therapeutic regimens that quiescent cancer cells might be resistant to and in which manner?

Does the future lie in combining chemotherapies that target proliferative cancer cells treatment that target quiescent CSCs?

\section{INTRODUCTION}

Many of the current chemotherapies are limited to merely targeting proliferative cancer cells. The residual population of chemotherapy-resistant tumor cells capable of regenerating the cancer disease is thought to be enriched in CSCs [1]. CSCs have the principal properties of self-renewal, clonal long-term repopulation potential, and the capability of producing non-stem daughter cells which make up the bulk of tumors [2]. Importantly, CSCs can enter a quiescent state, a reversible cell cycle arrest that is characterized by minimal basal metabolic activity. Recent advances suggest that quiescence is an actively maintained state in which signaling pathways are involved in maintaining a poised state [3]. The entry of the quiescence withstands metabolic stress and preserves its genomic integrity $[3,4]$. A recent study tracing glioma stem cells (GSCs) in a transgenic mouse model proved that the quiescent CSCs can survive from temozolomide [5]. In squamous cell carcinoma, TGF- $\beta$ concentrating near tumorvasculature bestows slower-cycling properties to neighboring CSCs, which show increased chemoresistance against cisplatin [6]. There is emerging evidence that the ability of CSCs to enter a quiescent state is an important driver of chemoresistance, leaving risks for tumor recurrence. For convenience, we summarize those chemotherapeutic agents which are reported to induce quiescent CSCs (Table 1).

Recent studies have shown that CSCs depend on different metabolic pathways compared to differentiated tumor cells, and the metabolic activities directly participate in the CSC

\footnotetext{
${ }^{1}$ Department of Hepatobiliary and Pancreatic Surgery, Affiliated Hangzhou First People's Hospital, Zhejiang University School of Medicine, Hangzhou, China. ${ }^{2}$ NHC Key Laboratory of Combined Multi-organ Transplantation, Hangzhou, China. ${ }^{3}$ Institute of Organ Transplantation, Zhejiang University, Hangzhou, China. ${ }^{4}$ Division of Hepatobiliary and Pancreatic Surgery, Department of Surgery, The First Affiliated Hospital, Zhejiang University School of Medicine, Hangzhou, China. ${ }^{5}$ These authors contributed equally: Kangchen Chen, Chenzhi Zhang. ${ }^{凶}$ email: zjxu@zju.edu.cn

Edited by Dr. Francesca Pentimalli
}

Received: 28 October 2020 Revised: 10 August 2021 Accepted: 20 August 2021

Published online: 04 September 2021 


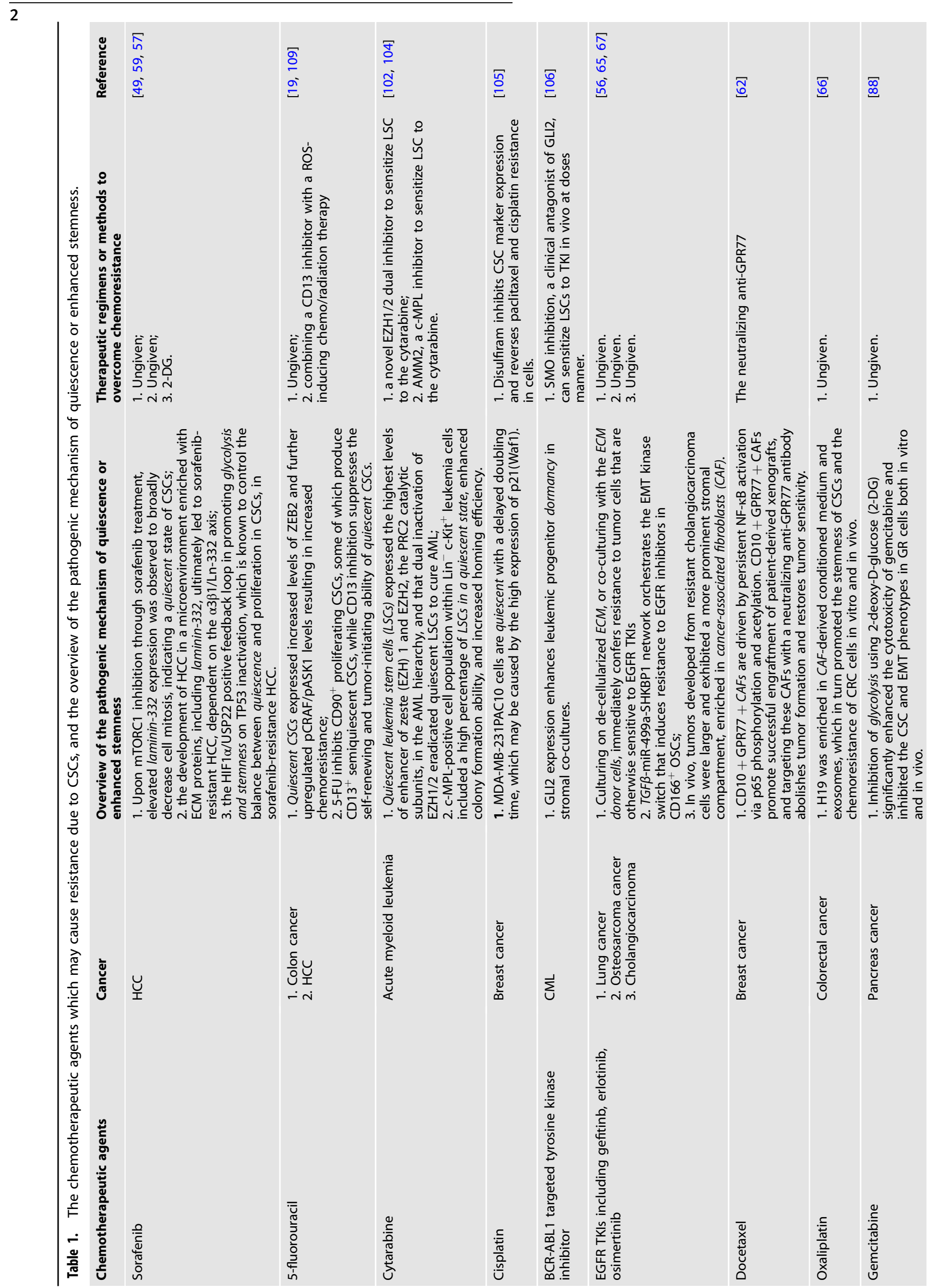


quiescent/proliferative states transition or support tumor progression [7]. CSCs can reprogram their metabolism to flexibly adapt to environmental changes, which is considered critical for them to enhance the antioxidant compensative capacity and sustain their self-renewal ability [8]. Quiescence is a mechanism whereby CSCs can be poised into a low metabolic state. Exploring the role of CSC metabolism and the mechanisms underlying metabolic flexibility has become a major focus in current cancer research. Changes in the environmental supply of metabolic substrates, intrinsic metabolic pathway disturbances by molecular mechanisms, altered reactive oxygen species (ROS) levels, and depolarized mitochondrial membranes of CSCs, may all contribute to quintessential metabolic reprogramming [9].

The CSC quiescence is also associated with the tumor microenvironment (TME), the environment around a tumor, including the surrounding blood vessels, immune cells, fibroblasts, signaling molecules, and the extracellular matrix $[10,11]$. The TME components stir the balance of quiescent/ proliferative CSCs, preserve their plasticity, and promote CSC stemness, thereby protecting them from immune system attack and resulting in chemotherapy failures $[12,13]$. In this review, we describe the roles of quiescent CSC and TME in chemoresistance, depict the metabolic flexibility of quiescent CSC, and further discuss the therapeutic potential of metabolism/TMEbased strategies for overcoming chemoresistance.

\section{MECHANISMS OF CSC CHEMORESISTANCE-THE MULTIPLE LINES OF SELF-DEFENSE Quiescence and chemoresistance}

As early as the 1970s, work on the hematologic malignancies predicted that slow-cycling leukemic stem cells cause tumor relapse [14, 15]. Investigators then observed that leukemic stem cells entered into the arrested cell cycle after chemotherapy, much like normal stem cells. The notion that recurrence after standard chemotherapy results from the persistence of quiescent CSCs has been supported recently in several solid tumor types $[5,6,16]$. As discussed below, CSCs trigger a set of complex intracellular molecular and epigenetic programs to enter quiescence, in response to chemotherapies [17].

Genetic and epigenetic modifications. Quiescent stem cells are poised for activation by specific energetically favorable mechanisms that are compatible with the low metabolic state of quiescence and that allow for rapid and global responses needed for activation [3]. The Notch, Wnt, and p38-MAPK signaling pathways are the most commonly involved in CSCs quiescence. Kobayashi et al. report that the active p38 mitogenactivated protein kinase 1 (MAPK1) can induce a quiescent state of CSC in prostate cancer [18]. Meanwhile, CSCs can quit the quiescent state under certain circumstances [19]. The Notch signaling and Wnt signaling pathways were reported to regulate adult stem cells division and differentiation, and recently they were proven to promote CSC reawakening $[20,21]$. Significantly, c-Myc, as a key element in Wnt canonical pathway, can accelerate the CSC cell cycle progression and promote CSC reawakening, while their inactivation was closely associated with the entry into reversible quiescence [22-25].

Epigenetic modifications consist of heritable changes in gene function without alteration of DNA sequence. Epigenetic modifications include DNA methylation, chromatin remodeling, and noncoding RNAs [26]. As cancers progress, epigenetic modifications regulate transcriptional activation, affecting the entry or exit of CSC into quiescence[27]. In fibroblasts, quiescent cells exhibit tighter chromatin compaction and increases of H4K20me2 and H4K20me3 (demethylation/trimethylation of histone $\mathrm{H} 4$ at lysine 20) [28]. Interestingly, $\mathrm{Ye}$ et al. documented that SET domain-containing protein 4 (SETD4) epigenetically induced quiescent breast CSCs (BCSCs) by facilitating tighter heterochromatin formation via H4K20me3 catalysis [29]. In melanoma, a small subset of slow-cycling cells with a doubling time of $>4$ weeks, which showed overexpression of the H3K4 demethylase JAR-ID1B, was reported to correlate with tumor progression and metastasis relapses [30]. In addition, Sharma et al. showed that growth arrestspecific 5 (GAS5), a long non-coding RNA, regulated the quiescent state (arrested cell-cycle) in the CD133+ pancreatic CSC population [31]. Taken together, these genetic and epigenetic modifications act as a switch for regulating quiescence and growth arrest in CSCs, which correlate with aggressive biology and chemoresistance of tumors.

Immune escape. Clinical evidence on the existence of the quiescent state of tumor cells came from the transmission of cancer from transplant organ donors to immunosuppressed recipients $[32,33]$. Under this condition, the immune system contains but not fully extinguishes cancer cell growth. Such cancer cells in immune escape can give rise to tumor recurrence or metastasis, once meeting permissive TME [34].

How do quiescent CSCs acquire immune tolerance? It has been proved that dormant cancer cells could evade immune surveillance by reducing antigenicity in lymphoma, fibrosarcoma, and T-lymphoma [35-37]. In addition, the expression of the immune checkpoints, such as programmed cell death ligand 1 (PD-L1), can protect cancer cells from $T$ cell killing activity [38]. In addition, the TME can help quiescent cells to escape immune surveillance. Vascular endothelial growth factor A (VEGFA) and angiopoietin-2 (ANGPT2; also known as ANG2) and IL- 6 secreted into the TME, concurrently upregulated the expression of the immune checkpoint ligand PD-L1 in tumors [39-41]. Apart from the T cells, natural killer cells may also be fooled by cunning quiescent CSCs. Massague lab showed that upon treatment with the WNT inhibitor DKK1, CSCs are forced into quiescence with the sharp decrease of ULBP (ligands for receptors expressed on NK cells, and NK1.1(+) T cells) and acquire the capability of evasion of NK-cell-mediated attack [42].

\section{The tumor microenvironment}

Hypoxic tumor microenvironment. Hypoxia has been identified as a hallmark of cancer [43]. Hypoxia within tumor occurs when the rate of rapidly dividing cancer cells in solid tumors quickly surpasses the rate of neovascularization within tumors. In these nutrient-depleted and oxygen-depleted areas, a hypoxic transcriptional response is orchestrated by hypoxia-inducible factors (HIFs) to make cancer cells adaptive to the hypoxic TME [44]. An increasing number of studies have attempted to unveil the complex but inseparable relationships between hypoxia and CSC phenotypes.

As demonstrated in many studies, a hypoxic environment induces the accumulation of HIF subunits in mesenchymal and cancer cells [45] that bind to hypoxia-responsive elements (HREs) in the promoters of hypoxia target genes [46, 47]. Among these subunits, HIF1a is the most studied and widely appreciated for its functions of supporting neovascularization, preventing cellular differentiation, controlling cellular apoptosis, and activating DNA repairment [48], all of which are associated with chemotherapy resistance. Recently, our laboratory unveiled that ubiquitin-specific protease 22 (USP22) can enhance the stability and transcriptional activity of HIF1a, and HIF1a only promoted USP22 transcription when TP53 was inactivated. Through the HIF1a/USP22 positive feedback loop of TP53 inactivation, hypoxic TME promotes stemness features (CD44+ and CD24+) and glycolysis in HCC cells, ultimately resulting in sorafenib resistance [49]. In colorectal cancer cells, CSN8 overexpression induces cell-cycle arrest, 
upregulates quiescence markers and hypoxia response genes (e.g., GLUT1), and enhances survival against 5-fluorouracil treatment [50]. In addition, hypoxia increases the expression of adenosine receptor $2 B(A 2 B R)$ in human breast cancer cells through the transcriptional activity of HIF1. The binding of adenosine to A2BR promotes breast CSC (BCSC) enrichment by activating protein kinase $C-\delta$, leading to increased expression of interleukin 6 and NANOG [51]. In addition, HIF1a also plays key roles in promoting CSC phenotypes through ITGA6 forkhead box protein M1 (FOXM1), miR-215, and signal transducer and activator of transcription 3 (STAT3) activation in breast cancer, pancreatic cancer, colon cancer, and glioma, respectively [52-55].

Driven by these mechanisms, a hypoxic TME is frequently associated with a more aggressive tumor phenotype. In addition, understanding the mechanism by which the hypoxic TME affects the quiescence of cancers may provide effective therapeutic opportunities.

\section{CSC-specific stroma and quiescent CSCs}

Extracellular matrix: As an indispensable factor in the TME, the ECM contributes to the induction of CSCs and the initiation of tumors. Interestingly, Wang et al. observed that the resistance to EGFR tyrosine kinase inhibitors (TKIs) was conferred to lung cancer cells that were originally sensitive to TKIs after culturing them on decellularized ECM or coculturing them with ECM donor cells [56]. Azzariti et al. also reported that the development of HCC in a microenvironment enriched with ECM proteins, including laminin332 , ultimately led to sorafenib-resistant HCC, dependent on the a3 $31 / \mathrm{Ln}-332$ axis [57]. Among the many components of the ECM that are putatively regarded as initiating factors of chemoresistance, laminin has recently received special attention.

Laminin is a glycoprotein ECM component of the connective tissue basement membrane that promotes cell adhesion. Rohn et al. isolated rat hepatic stellate cells and then seeded them onto uncoated polystyrene (PS) or PS coated with either laminin-521 (PS/LN-521) or laminin-211 (PS/LN-211). PS/LN-521 improved hepatic stellate cells adhesion and better-preserved retinoid stores, as well as quiescence-associated and stem cell-associated phenotypes than PS alone [58]. Moreover, laminin-332 was also observed in the ECM surrounding hepatic CSC-like cells which exhibited a low proliferation rate. Upon mTORC1 inhibition through sorafenib treatment, elevated laminin-332 expression was observed to broadly decrease CSCs mitosis, indicating a quiescent state in CSCs [59]. Taken together, the above results demonstrate that the quiescent state of CSCs is closely linked to the ECM and its components.

Cancer-associated fibroblast: Given the important role of the ECM on cancer stemness, cancer-associated fibroblasts (CAFs), as the primary source of ECM production in tumors, are also worthy of our comprehensive discussion. CAFs affect tumor progression and resistance via many mechanisms, including morbid secretion of collagens, fibronectins, and ECM-degrading proteases, production of angiogenic factors, and various proinflammatory cytokines and chemokines $[60,61]$. Here, we will emphasize the role of CAFs in promoting cancer stemness.

$\mathrm{Su}$ et al. showed that co-injection of $\mathrm{CD} 10^{+} \mathrm{GPR} 77^{+} \mathrm{CAFs}$ and breast cancer cells effectively improved the engraftment formation in patient-derived xenograft models. Most importantly, the CAF subset specifically defined by CD10 and GPR77 expression was observed to be correlated with chemoresistance and poor survival in multiple cohorts of breast and lung cancer patients [62]. Liu et al. concluded that CAF-induced lysine demethylase 1 (LSD1, a histone-modifying enzyme) activation in hepatic CSCs can enable their self-renewal ability in HCC. The authors inoculated a mixture of liver CSCs $\left(C_{\text {Cherry }}^{+}-\mathrm{GFP}^{+}\right)$and primary CAFs into NOD/ SCID mice, and as expected, CAFs enhanced the oncogenicity of CSCs by activating Notch3-LSD1 signaling in vivo [63]. Similar carcinogenic effects of CAFs have been reported in colorectal cancer, cholangiocarcinoma, oral squamous cell carcinoma, and osteosarcoma cancer [64-67].

Matrix stiffness. Tissue formation and development originating from stem cells are orchestrated by a complex network of both chemical and physical properties, but recently researchers have started to focus on the effects of matrix stiffness on CSC and chemoresistance.

Matrix stiffness (rigidity of extracellular matrix) is mainly depending on the composition and organization of ECM [68]. Huang's laboratory proved that cancer cells effectively form spheroid-like morphologic shapes resembling stem-like cells in $90 \mathrm{~Pa}$ fibrinogen gels (the stiffness of most mammalian tissues ranges from approximately 100 to $3000 \mathrm{~Pa}$ ), while their growth was retarded in $450 \mathrm{~Pa}$ and almost entirely halted in $1050 \mathrm{~Pa}$ [10]. In addition, Liu et al. showed that the CSC dormancy induced by 450 and $1050 \mathrm{~Pa}$ was initiated by the translocation from the cytoplasm to the nucleus of $\mathrm{Cdc42}$, a regulatory protein capable of mechanotransduction [69]. Meanwhile, Shin et al. confirmed the pathological correlation of matrix stiffness and drug sensitivity against standard chemotherapies of myeloid leukemias in vivo, such as everolimus [70].

Traditional views of the TME solely based on cell-cell or cell-ECM interactions may not thoroughly explain the induction, selection, or preferential maintenance of CSC stemness. Thus, gaining a comprehensive understanding of the interplay between CSCs and their microenvironments may be essential for advancing CSC research and applications (summarized in Fig. 1).

\section{Other mechanisms of chemoresistance}

Other defense lines of CSCs include avoiding cellular and molecular exposure to the drugs, avoiding conditions needed for the drugs to act, damage repair, anti-apoptosis, and regeneration [71]. But their relationships with cancer quiescence remain unveiled, so they are not discussed further in this article.

\section{METABOLIC FLEXIBILITY}

CSCs can reprogram their metabolism to flexibly adapt to environmental changes, which is considered crucial for them to enhance the antioxidant compensative capacity and sustain their self-renewal ability $[8,72]$. For example, activation of the glycolytic program in CSCs can enhance their antioxidative capacity, where the pentose phosphate pathway (PPP) is the most relevant and produces reduced intermediates, such as NADPH [72, 73].

Proliferative CSC needs massive biosynthetic materials and an oxidation state to remain growing, while quiescent CSC retains a reduction state for prevention from cell death and injury. It was documented by Anderson et al. that ovarian CSCs were highly flexible/plastic in metabolic phenotypes [74]. Ovarian CSCs were able to accelerate the rate of glycolysis to overcome the ATP inhibition by oligomycin treatment, but conversely, they could also increase the oxygen consumption rate to maintain the proton motive force [74]. Indeed, the metabolic flexibility is not confined to mutual shift between glycolysis and OXPHOS, but also between glycolysis and glutamine metabolism. In colorectal cancer, the metformin-sensitive HT29 cell line showed higher OXPHOS levels, while SW620 cells were metformin-resistant and had lower OXPHOS levels. When glutamine was removed from the culture medium, SW620 cells surprisingly became sensitive to metformin, with decreased expression of stemness biomarkers [75].

Crucially, quiescence is a mechanism by which CSCs can be maintained in a low metabolic state, and such a low metabolic state of quiescence is always accompanied by enhanced antioxidant defenses. Oxidative stress was observed to trigger the transition from ROS-low quiescent mesenchymal-like BCSCs (M-BCSCs) to ROS-high proliferative epithelial-like ones (E-BCSCs) 


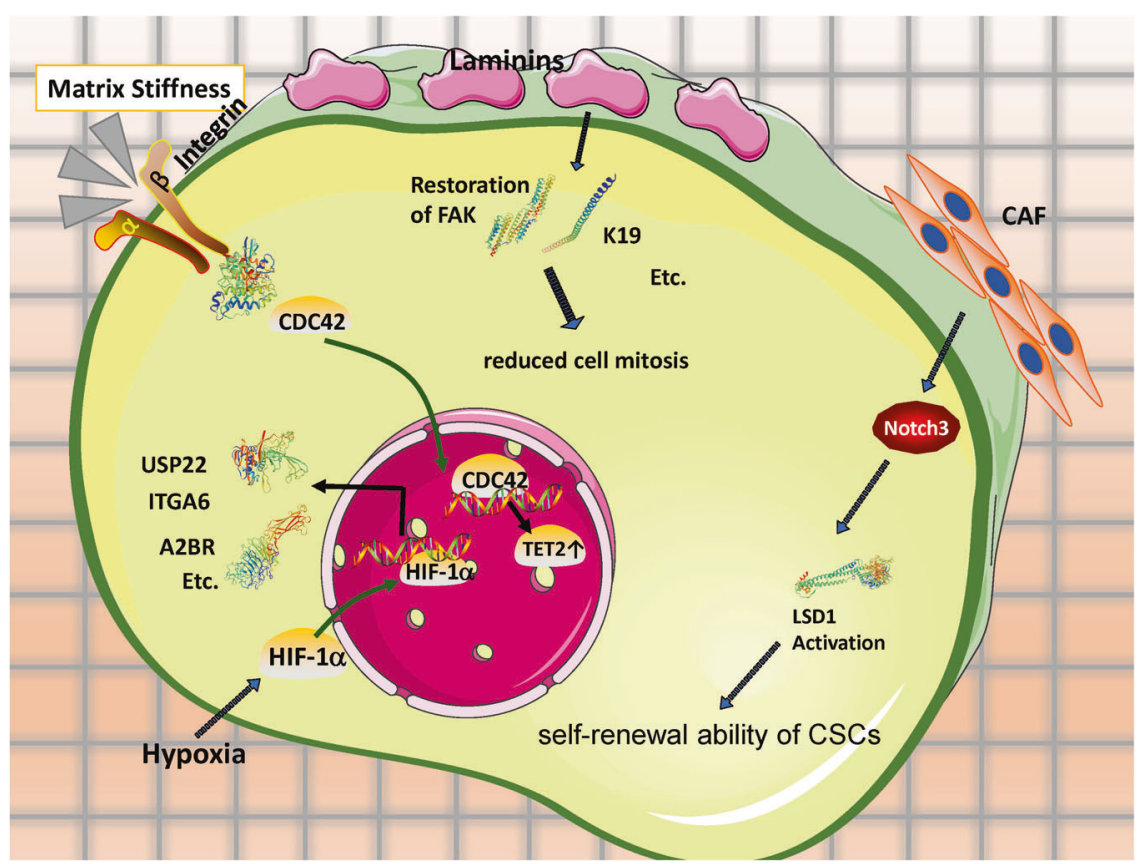

Fig. 1 Quiescent CSCs are responsible for refractoriness to chemotherapies via crosstalk of chemical and mechanical signals from TME components, including hypoxia, ECM, CAFs, and matrix stiffness. Through the utilization of antioxidants and available metabolic substrates, CSCs "equips" themselves with metabolic flexibility to maintain themselves quiescent in response to stress and different metabolic austerity. Crucially, inhibition of the morbidly-activated metabolic pathways on which quiescent CSCs are dependent, show promises on chemotherapy sensitization.

[76]. Moreover, increasing evidence demonstrates that glutamine (Gln), as the substrate of reduced glutathione (GSH), also plays a key role in the antioxidant system and serves as an energy source for CSCs [77]. Taken together, lower levels of ROS or enhanced GSH are closely related to the quiescent states of CSC, and even chemoresistance $[78,79]$. Reviews of primary metabolic pathways of various CSCs (summarized in Fig. 2) may help to identify quiescent CSCs genes and pathways that maintain the quiescent stem cell state, rendering those cells poised for activation.

\section{CSC quiescence: balance of excessive ROS and glycolysis}

Many studies have revealed that CSCs are prone to exhibiting a glycolytic phenotype compared with their descendants. Indeed, aerobic or anaerobic glycolysis contributes to maintaining CSC phenotypes under specific conditions, such as hypoxia and nutrient limitation [80-82]. As we mentioned above, the quiescent M-BCSCs exhibit higher glycolytic rates in glucose-rich culturing conditions [76]. Theoretically, activation of the glycolytic program can enhance antioxidative capacity, with the PPP being the most relevant and capable of rapidly providing NADPH to meet the massive biosynthetic demand of GSH, which counteracts excessive ROS [83]. Indeed, the quiescent state of CSC is reported to be closely related to lower levels of ROS or enhanced GSH in various cancers [76, 84, 85].

As for the impact of glycolysis on CSC quiescence, glycolysis is considered crucial for CSCs to sustain their antioxidant compensative capacity, enhance stemness, and improve self-renewal ability $[9,49,76,86-92]$. As shown in Table 2, abnormally increased levels of glycolytic intermediates or products from glycolysis, such as lactate, serine/glycine, and glutamine, have been identified as markers of enhanced CSC stemness and chemotherapy resistance. Given that CSC quiescence ties up with drug sensitivity, it is reasonable to presume that abnormal glycolysis of CSC possibly functions as an initiating factor of chemoresistance. Those metabolic enzymes that initiate the metabolic flexibility to glycolysis are regarded as potential targets to inhibit CSC stemness.
Oxidative phosphorylation "addiction"

Although many studies have reported that CSCs tend to shift from OXPHOS to glycolysis when facing a nutritional or oxygen supply shortage, OXPHOS is also reported to equip certain CSCs with increased survival from metabolic austerity [81]. OXPHOS can be the primary source of energy and biosynthesis in specific cases as well [74, 93-96]. Here, we review five articles that propose OXPHOS to be the dominant energy resource to maintain CSCs' self-renewal and tumourigenesis (summarized in Table 3).

Vlashi et al. first observed that GSCs and their progenitor cells are less glycolytic than differentiated glioma cells. Their laboratory previously reported that GSCs have lower 26 S proteasome activity than nontumorigenic cells [97], and they took advantage of this feature to monitor GSCs in real-time using the fluorescent protein ZsGreen. The GSCs were observed to consume less glucose and produce less lactate while maintaining higher ATP levels than their differentiated progeny [93]. A similar story in gliomaspheres and lung CSCs soon followed this study by Janiszewska et al. [94] and Lin et al. [95]. In addition, Sancho et al. also demonstrated that while pancreatic non-CSCs are heavily dependent on glycolytic substrates, pancreatic CSCs strictly depend on OXPHOS to sustain their vitality. When the CSCs were confronted with mitochondrial respiration inhibition (e.g., metformin administration), they rapidly underwent an energy crisis and apoptosis induced by inhibition of MYC [96].

Indeed, OXPHOS acts as a far more efficient source of ATP production than glycolysis. These OXPHOS-dependent CSCs make efficient use of specific limited nutrients, allowing them to obtain a selective advantage in certain TMEs.

\section{Potential role of glutamine in CSCs}

Overall, most CSC primarily relies on either glycolysis or OXPHOS [98]. However, with the development of tracer techniques, increasing evidence demonstrates that Gln is also an important metabolic substrate and energy source for CSCs [99]. Here, we review articles with results indicating that glutamine and/or 


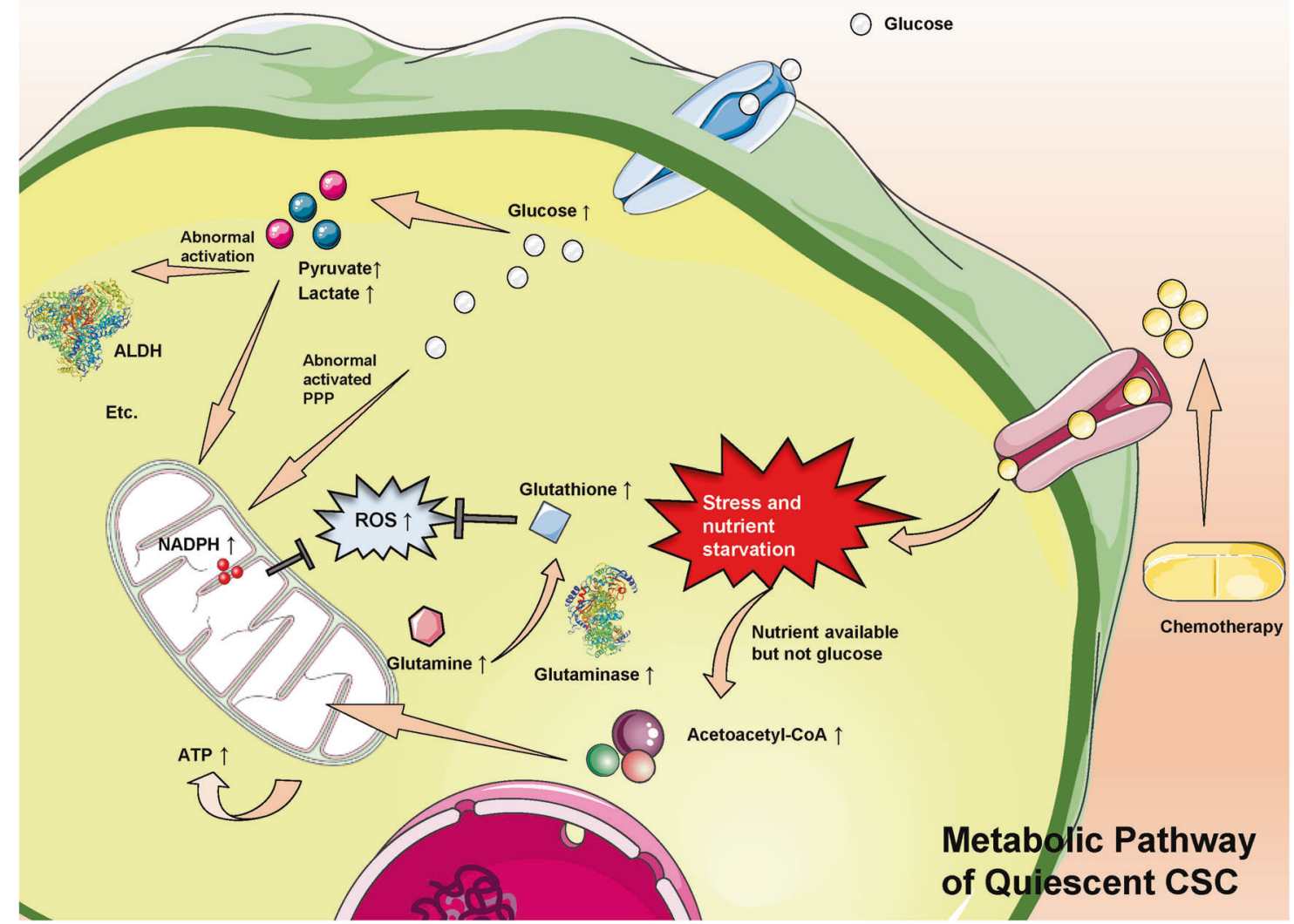

Fig. 2 Chemotherapy drugs are taken up by cancer cells, causing stress and nutrient starvation. Through the pentose phosphate pathway, glucose can indirectly produce NADPH, which confronts excessive intracellular ROS to maintain CSC in the quiescent state. Second, when nutrients in the TME are in short, nutrients excluding glucose are decomposed and go through OXPHOS to effectively produce ATP to sustain basic biological demand. Third, glutathione also can be synthesized from glutamine (an important and rich non-essential amino acid) and participate in the self-defense mechanism in response to excessive ROS and reduce its related adverse outcomes. Meanwhile, the intermediates in glycolysis, pyruvate, and lactate further can abnormally activate ALDH, initiating or strengthening CSC stemness.

glutamate play a significant role in maintaining the stemness of CSCs.

Liao et al. introduced L-asparaginase, an enzyme that catalyses the conversion of glutamine to glutamate, into the culture medium of human non-small-cell lung carcinoma (NSCLC)and pancreatic cancer cells to mimic the effect of decreasing glutamine. Mechanistically, glutamine exhaustion results in an enhancement of intracellular ROS levels through attenuation of the cellular levels of reduced GSH (a derivative of glutamine), ultimately leading to a decreased proportion of CSCs in the tumor in vivo [99]. In addition, there were two indirect lines of evidence. First, knockdown of glutaminase (GLS) 1 significantly suppressed the expression of stemness-related genes, such as CD13 and CD133, and inhibited CSC pool expansion in vitro and tumorigenicity in vivo [100]. Second, a similar result was that GLS1 functioned in accordance with ALDH to maintain cancer stemness in head and neck squamous cell carcinoma [101]. The authors did not deplete or augment the concentration of glutamine in the culture medium in vitro or tissue in vivo; however, given that the function of GLS to hydrolyze glutamine to glutamate was well acknowledged, the role of glutamine in the maintenance of stemness was not negligible.

\section{'WAKING UP' QUIESCENT CSCS TO OVERCOME CHEMORESISTANCE \\ Therapies targeting CSCs}

Resident quiescent CSCs made the prognosis of patients treacherous after chemotherapeutic treatment [102-112]. Even though preventing the activation of quiescent cells has been successful in experimental models [113-116], keeping CSCs longterm dormant may not be feasible in patients. Direct therapeutic elimination of quiescent CSCs awaits a better understanding of their vulnerabilities. Another strategy of overcoming chemoresistance consists of 'waking up' this cell population into a differentiated state, making them susceptive to chemotherapies.

All-trans retinoic acid. The idea of 'waking up' CSCs into a susceptive state to therapies arose from the observation that chemo-resistant leukemic cells became susceptive when they were induced from an undifferentiated state into a differentiated one by the use of all-trans retinoic acid (ATRA) [117]. The success of ATRA therapy inspired other therapies that were based on inducing CSC differentiation in other leukemic malignancies (reviewed by Stahl et al. [118]). However, it was first studied in solid tumors with a well-explored mechanism by Moro et al. [111]. Pretreatment with ATRA, which causes CSCs to differentiate, counteracts cisplatin resistance originating from quiescent NSCLC

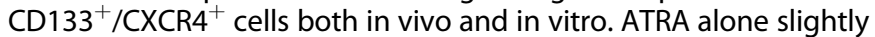
decreases the percentage of CD133+ cells without affecting tumor growth, further demonstrating that ATRA only sensitizes CSCs rather than killing them directly.

2-Deoxy-D-glucose. As mentioned above, quiescence is a mechanism whereby CSCs can be poised into a low metabolic state, therefore, interference with intracellular metabolism shows good practical value and application prospect. 2-deoxy-D-glucose (2-DG) is a glucose molecule that has the 2-hydroxyl group 


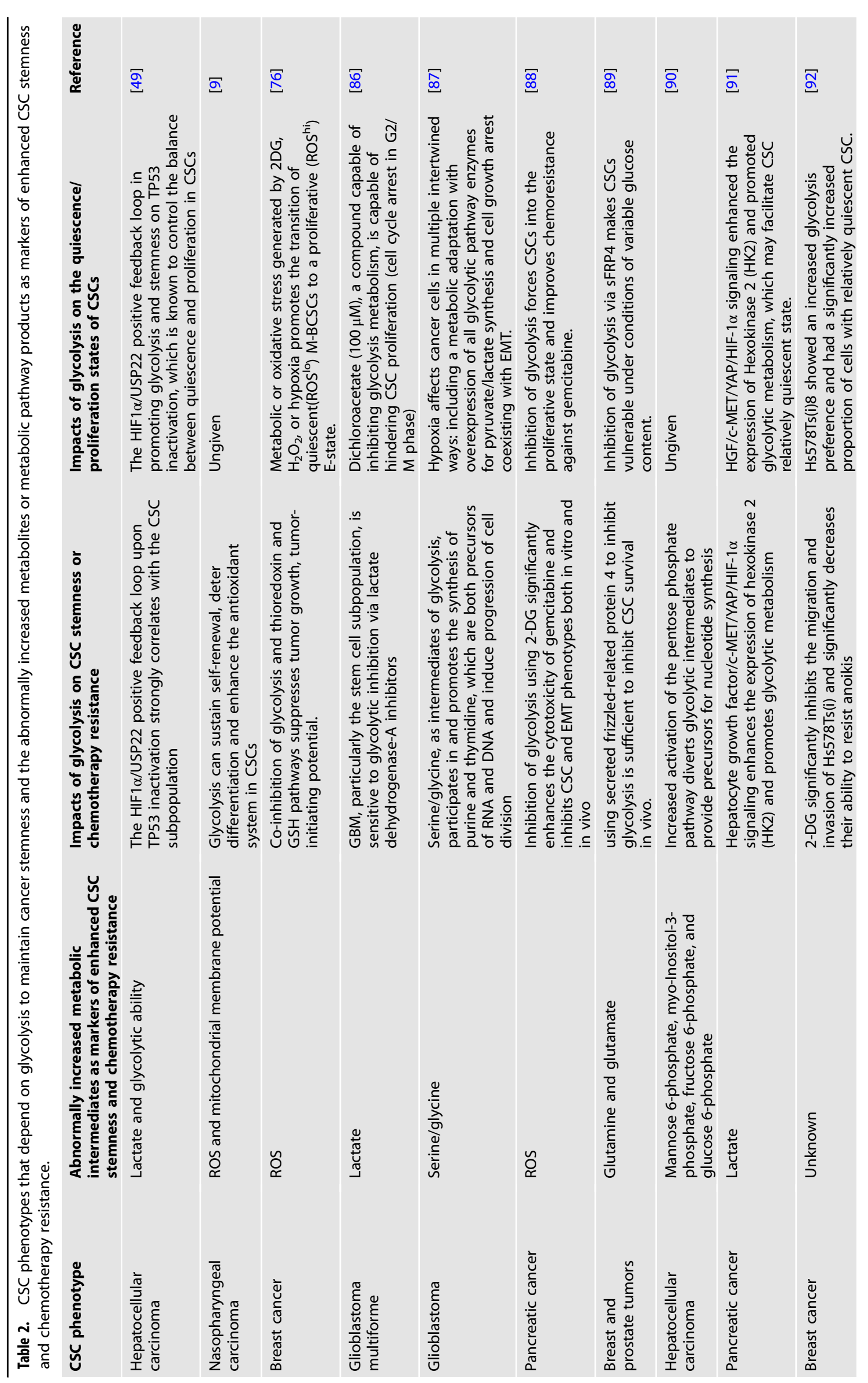




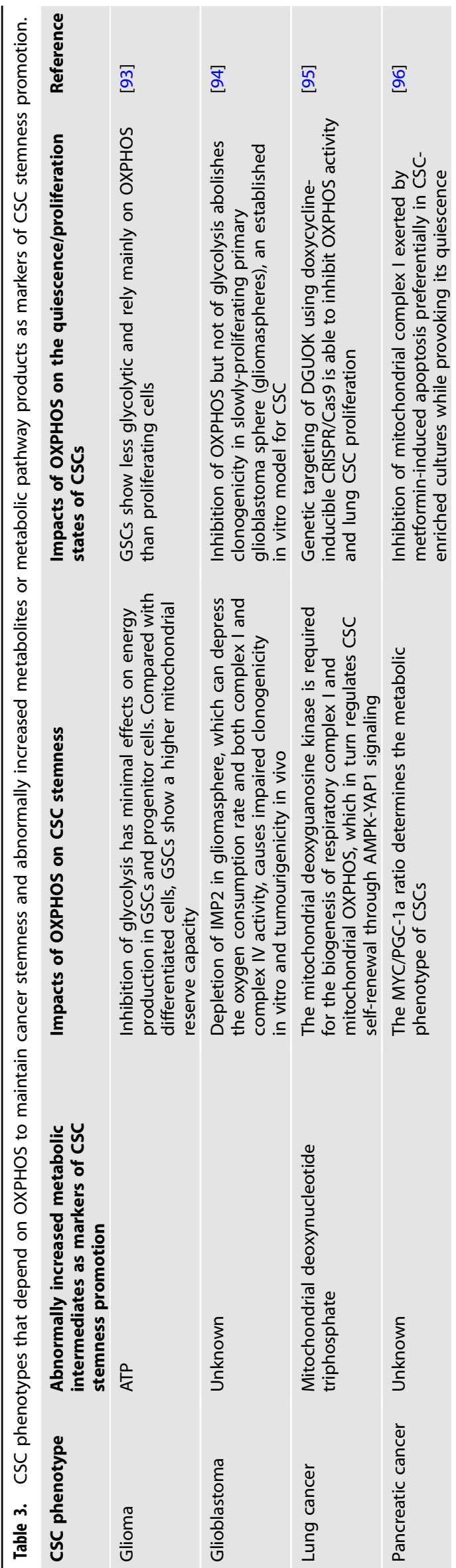

replaced by hydrogen, and it interferes with d-glucose metabolism. There is an increasing focus on using 2-DG to ameliorate resistance to cytotoxic therapies. For example, in triple-negative breast cancer, the more aggressive Hs578Ts(i)8 variant with a significantly increased proportion of CSC phenotype showed an enhanced ability to resist anoikis than its parental cells [92]. Furthermore, Hs578Ts(i)8 exhibited a significantly increased glycolysis flux rather than mitochondrial OXPHOS. After 2-DG was introduced, Hs578Ts(i)8 significantly decreased its ability to resist anoikis. A similar story was reported in Gemcitabine-resistant (GR) pancreatic CSCs. The cytotoxicity of gemcitabine towards GR cells was significantly enhanced when combined with the 2-DG, manifested by the inhibition of the CSC stemness and the EMT phenotypes both in vitro and in vivo [88].

Previous studies have proved that CSCs possess relatively low intracellular ROS levels, especially in those quiescent ones. To be more specific, the increase of ROS by glycolysis disruption may lead to the differentiation into non-CSCs and the loss of stemness markers [119-121]. Therefore, disrupting ROS equilibrium within quiescent CSCs by 2-DG may be a potential adjuvant to reverse chemoresistance.

Oligomycin and rotenone. Oligomycin and rotenone are both mitochondrial OXPHOS Complex inhibitors. Gale et al. reported that combining ATP synthase inhibitor oligomycin A with trastuzumab led to regression of trastuzumab-resistant breast HER2 + tumors in vivo [122]. Matassa et al. also demonstrated that in ovarian cancer, TRAP1 silencing induced resistance to cisplatin, and chemoresistant cells showed over-activated OXPHOS compared with the sensitive counterpart. More strikingly, cisplatin resistance was reversible upon inhibition by metformin/oligomycin [123]. In doxorubicin(DOX)-resistant breast cancer cells, mitochondrial accumulation of DOX in tumor cells was increased by treatment with oligomycin, that is, chemoresistance to DOX was partially reversed at least.

Besides oligomycin A, rotenone also drew some focuses. CruzBermúdez et al. demonstrated that metabolic flexibility from glycolysis to OXPHOS was responsible for cisplatin resistance in NSCLC, and strikingly, the chemoresistance could be reversed by OXPHOS inhibition using metformin or rotenone [124].

Other drugs sensitizing CSCs to chemotherapies. Yang et al. used disulfiram (DSF), an inhibitor of ALDH enzyme activity, to induce quiescent-dominated CSCs into proliferative-dominated states and enhance the cytotoxic effect of cisplatin in breast cancer [125]. Similar tactics have been manifested by Jamieson's laboratory using PF-04449913, also named glasdegib, to sensitize blast crisis LSCs to TKI in vivo at doses that do not affect normal hematopoietic stem cells [106]. Helgason's laboratory observed that lys 05 , a highly potent lysosomotropic agent, could promote autophagy inhibition, reverse leukemic stem cell quiescence and drive myeloid cell expansion [107].

\section{Therapies targeting CSC-specific stroma}

Since the TME has the potential to support and initiate stem celllike programs in cancer cells, targeting the TME components may prove to be a powerful modality for the prevention of chemotherapy resistance. CAFs remodel the tumor ECM and architecture of the TME, leading to poor infiltration of traditional chemotherapies and increased drug resistance. There is an innovative method of preventing chemoresistance by forcing activated CAFs back into quiescence. Sherman et al. documented that vitamin D receptor was over-activated in pancreatic CAFs that could drive tumorigenesis. Importantly, reversion to the quiescent state of CAFs using calcipotriol (a vitamin D analog) witnessed induced stromal remodeling, increased intratumoral gemcitabine infiltration, reduced pancreatic tumor volume, and a $57 \%$ sharp increase in survival compared to chemotherapy alone [126]. Aside 
from calcipotriol, similar findings were reported with ATRA as well. In 3D models and genetic mouse models of PDAC, the use of ATRC to restore the quiescence of CAFs in TME increased vascularity within tumors, improving response to gemcitabine and reducing tumor growth [127].

Considering the presence of CSCs after traditional chemotherapy, treatments for CAFs may have better outcomes when they are combined with traditional chemotherapy.

\section{CONCLUSION AND PERSPECTIVES}

There is now solid evidence to support the hypothesis that quiescent CSCs give rise to the refractoriness of chemotherapies in many cancer types. New insights into CSC biology suggest that strategies merely inhibiting CSC stemness characteristics might not suffice to counteract tumor recurrence. The TME maintains the principle properties of CSCs, protects them from immune surveillance, and facilitates their relapse potential. The TME does not only provide various signals that maintain resident quiescent CSCs but also instructs progenitor cells to revert into a stem cell state when the originals are lost [128]. Thus, targeting the TME components may be a more effective strategy for the treatment of chemoresistance than inhibiting the CSCs stemness directly. In addition, through the utilization of antioxidants and metabolic fuels, CSCs "equips" themselves with the metabolic flexibility to maintain themselves quiescent in response to stress and different metabolic austerity [74]. Significantly, primary metabolic pathways of various CSCs are reprogrammed for maintenance in CSCs quiescence, the poised state, but also can be utilized as an effective target of eliminating quiescent CSCs and attenuating resistance to chemotherapies (Fig. 3).

Recently, via molecular imaging methods, such as $\mathrm{F}^{-18}$-fluoro-2deoxy-D-glucose $\left(\mathrm{F}^{-18}\right.$-FDG) positron emission tomography, magnetic resonance imaging, and optical imaging based on the fluorescent protein and principal properties of CSCs, the peritumoral microenvironment can be monitored in real-time and serve as a reflection of the metabolic phenotype of CSCs [97]. With the development of such techniques and methodologies in metabolic research, the measurement of metabolites in the TME

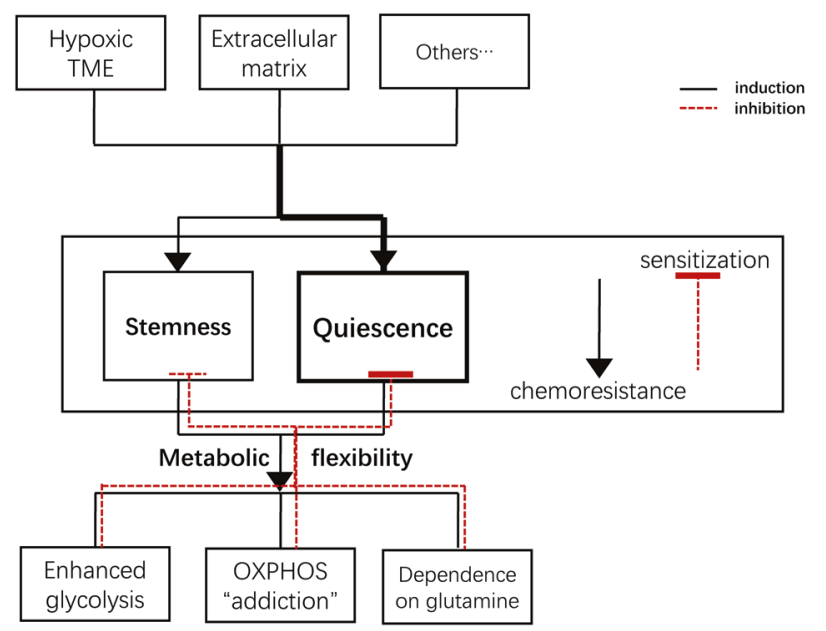

Fig. 3 Flow diagram of quiescent CSCs initiation and their metabolic reprogramming. Quiescent $\mathrm{CSCs}$ are induced and maintained by different TME components, including a hypoxic tumor environment, laminins, and matrix stiffness of the ECM and CAFs. Quiescent CSCs can reprogram their metabolism to flexibly adapt to environmental changes, which is considered crucial for them to enhance the antioxidant compensative capacity and induce chemotherapy resistance. And it is a promising strategy of making them susceptive to chemotherapies through inhibition of their metabolic flexibility. can be used to unveil the metabolic phenotype and quiescent/ proliferative state of CSCs, providing timely warning of potential chemoresistance and suggestions for the application of antitumor treatments.

\section{REFERENCES}

1. Batlle E, Clevers H. Cancer stem cells revisited. Nat Med. 2017;23:1124-34.

2. Plaks V, Kong N, Werb $Z$. The cancer stem cell niche: how essential is the niche in regulating stemness of tumor cells? Cell Stem Cell. 2015;16:225-38.

3. Cheung TH, Rando TA. Molecular regulation of stem cell quiescence. Nat Rev Mol Cell Biol. 2013;14:329-40.

4. Ishikawa F, Yoshida S, Saito $Y$, Hijikata A, Kitamura $H$, Tanaka $S$, et al. Chemotherapy-resistant human AML stem cells home to and engraft within the bone-marrow endosteal region. Nat Biotechnol. 2007:25:1315-21.

5. Chen J, Li Y, Yu TS, McKay RM, Burns DK, Kernie SG, et al. A restricted cell population propagates glioblastoma growth after chemotherapy. Nature. 2012;488:522-6.

6. Oshimori N, Oristian D, Fuchs E. TGF- $\beta$ promotes heterogeneity and drug resistance in squamous cell carcinoma. Cell. 2015;160:963-76.

7. Chae YC, Kim JH. Cancer stem cell metabolism: target for cancer therapy. BMB Rep. 2018;51:319-26.

8. Tanabe A, Sahara $\mathrm{H}$. The metabolic heterogeneity and flexibility of cancer stem cells. Cancers. 2020;12:2780.

9. Shen Y-A, Wang C-Y, Hsieh Y-T, Chen Y-J, Wei Y-H. Metabolic reprogramming orchestrates cancer stem cell properties in nasopharyngeal carcinoma. Cell Cycle. 2015;14:86-98.

10. Liu J, Tan $Y$, Zhang H, Zhang $Y, X u$ P, Chen J, et al. Soft fibrin gels promote selection and growth of tumorigenic cells. Nat Mater. 2012;11:734-41.

11. Park D, Lim J, Park JY, Lee S-H. Concise review: stem cell microenvironment on a chip: current technologies for tissue engineering and stem cell biology. Stem Cells Transl Med. 2015;4:1352-68.

12. Batlle $\mathrm{E}$, Clevers $\mathrm{H}$. Cancer stem cells revisited. Nat Med. 2017;23:1124-34.

13. Dean M, Fojo T, Bates S. Tumour stem cells and drug resistance. Nat Rev Cancer. 2005;5:275-84.

14. Cronkite EP. Acute leukemia: is there a relationship between cell growth kinetics and response to chemotherapy? Proc Natl Cancer Conf. 1970;6:113-7.

15. Clarkson BD. Review of recent studies of cellular proliferation in acute leukemia. Natl Cancer Inst Monogr. 1969;30:81-120.

16. Kreso A, O'Brien CA, van Galen P, Gan Ol, Notta F, Brown AM, et al. Variable clonal repopulation dynamics influence chemotherapy response in colorectal cancer. Science. 2013:339:543-8.

17. Talukdar S, Bhoopathi P, Emdad L, Das S, Sarkar D, Fisher PB. Dormancy and cancer stem cells: An enigma for cancer therapeutic targeting. Adv Cancer Res. 2019;141:43-84.

18. Kobayashi A, Okuda $H$, Xing F, Pandey PR, Watabe M, Hirota $S$, et al. Bone morphogenetic protein 7 in dormancy and metastasis of prostate cancer stemlike cells in bone. J Exp Med. 2011;208:2641-55.

19. Francescangeli F, Patrizii M, Signore M, Federici G, Di Franco S, Pagliuca A, et al. Proliferation state and polo-like kinase1 dependence of tumorigenic colon cancer cells. Stem Cells. 2012:30:1819-30.

20. Abravanel DL, Belka GK, Pan TC, Pant DK, Collins MA, Sterner CJ, et al. Notch promotes recurrence of dormant tumor cells following HER2/neu-targeted therapy. J Clin Invest. 2015;125:2484-96.

21. Nguyen DX, Chiang AC, Zhang XH, Kim JY, Kris MG, Ladanyi M, et al. WNT/TCF signaling through LEF1 and HOXB9 mediates lung adenocarcinoma metastasis. Cell. 2009;138:51-62.

22. Yang A, Qin S, Schulte BA, Ethier SP, Tew KD, Wang GY. MYC inhibition depletes cancer stem-like cells in triple-negative breast cancer. Cancer Res. 2017:77:6641-50.

23. Civenni G, Malek A, Albino D, Garcia-Escudero R, Napoli S, Di Marco S, et al. RNAi-mediated silencing of Myc transcription inhibits stem-like cell maintenance and tumorigenicity in prostate cancer. Cancer Res. 2013;73:6816-27.

24. Wu CH, van Riggelen J, Yetil A, Fan AC, Bachireddy P, Felsher DW. Cellular senescence is an important mechanism of tumor regression upon c-Myc inactivation. Proc Natl Acad Sci USA. 2007;104:13028-33.

25. Shachaf CM, Kopelman AM, Arvanitis C, Karlsson A, Beer S, Mandl S, et al. MYC inactivation uncovers pluripotent differentiation and tumour dormancy in hepatocellular cancer. Nature. 2004;431:1112-7.

26. Pacchierotti F, Cordelli E, Russo A. Environmental Effects on Developing Germ Cells. In:Skinner MK, editor. Encyclopedia of Reproduction. Second Edition. Oxford: Academic Press; 2018. pp. 452-8.

27. Ferrer Al, Trinidad JR, Sandiford O, Etchegaray JP, Rameshwar P. Epigenetic dynamics in cancer stem cell dormancy. Cancer Metastasis Rev. 2020;39:721-38. 
28. Evertts AG, Manning AL, Wang X, Dyson NJ, Garcia BA, Coller HA. H4K20 methylation regulates quiescence and chromatin compaction. Mol Biol Cell. 2013;24:3025-37.

29. Ye S, Ding YF, Jia WH, Liu XL, Feng JY, Zhu Q, et al. SET domain-containing protein 4 epigenetically controls breast cancer stem cell quiescence. Cancer Res. 2019;79:4729-4743.

30. Roesch A, Fukunaga-Kalabis M, Schmidt EC, Zabierowski SE, Brafford PA, Vultur A, et al. A temporarily distinct subpopulation of slow-cycling melanoma cells is required for continuous tumor growth. Cell. 2010;141:583-94.

31. Sharma NS, Gnamlin P, Durden B, Gupta VK, Kesh K, Garrido VT, et al. Long noncoding RNA GAS5 acts as proliferation "brakes" in CD133+ cells responsible for tumor recurrence. Oncogenesis. 2019;8:68.

32. Buell JF, Beebe TM, Trofe J, Gross TG, Alloway RR, Hanaway MJ, et al. Donor transmitted malignancies. Ann Transplant. 2004;9:53-6.

33. Penn I. Malignant melanoma in organ allograft recipients. Transplantation 1996;61:274-8.

34. Dunn GP, Old LJ, Schreiber RD. The three Es of cancer immunoediting. Annu Rev Immunol. 2004;22:329-60.

35. Müller M, Gounari F, Prifti S, Hacker HJ, Schirrmacher V, Khazaie K. EblacZ tumor dormancy in bone marrow and lymph nodes: active control of proliferating tumor cells by CD8+ immune T cells. Cancer Res. 1998;58:5439-46.

36. Romero I, Garrido C, Algarra I, Collado A, Garrido F, Garcia-Lora AM. T lymphocytes restrain spontaneous metastases in permanent dormancy. Cancer Res. 2014;74:1958-68.

37. Mahnke YD, Schwendemann J, Beckhove $P$, Schirrmacher V. Maintenance of long-term tumour-specific T-cell memory by residual dormant tumour cells. Immunology. 2005;115:325-36.

38. Dieterich LC, Ikenberg K, Cetintas T, Kapaklikaya K, Hutmacher C, Detmar M. Tumor-Associated Lymphatic Vessels Upregulate PDL1 to Inhibit T-Cell Activation. Front Immunol. 2017;8:66.

39. Schmittnaegel M, Rigamonti N, Kadioglu E, Cassará A, Wyser Rmili C, Kiialainen $A$, et al. Dual angiopoietin-2 and VEGFA inhibition elicits antitumor immunity that is enhanced by PD-1 checkpoint blockade. Sci Transl Med. 2017;9:eaak9670.

40. Bichsel CA, Wang L, Froment $L$, Berezowska S, Müller $S$, Dorn $P$, et al. Increased PD-L1 expression and IL-6 secretion characterize human lung tumor-derived perivascular-like cells that promote vascular leakage in a perfusable microvasculature model. Sci Rep. 2017;7:10636.

41. Wang Q, Gao J, Di W, Wu X. Anti-angiogenesis therapy overcomes the innate resistance to PD-1/PD-L1 blockade in VEGFA-overexpressed mouse tumor models. Cancer Immunol Immunother. 2020;69:1781-99.

42. Malladi S, Macalinao DG, Jin X, He L, Basnet $H$, Zou $Y$, et al. Metastatic latency and immune evasion through autocrine inhibition of WNT. Cell. 2016;165:45-60.

43. Kim Hoon, Lin Qun, Glazer PeterM, Yun Zhong. The hypoxic tumor microenvironment in vivo selects the cancer stem cell fate of breast cancer cells. Breast Cancer Res. 2018;20:16.

44. Semenza GL. Targeting HIF-1 for cancer therapy. Nat Rev Cancer. 2003;3:721-32.

45. Wang GL, Semenza GL. General involvement of hypoxia-inducible factor 1 in transcriptional response to hypoxia. Proc Natl Acad Sci USA. 1993;90:4304-8.

46. Li Z, Bao S, Wu Q, Wang H, Eyler C, Sathornsumetee $S$, et al. Hypoxia-inducible factors regulate tumorigenic capacity of glioma stem cells. Cancer Cell. 2009;15:501-13.

47. Schonberg DL, Lubelski D, Miller TE, Rich JN. Brain tumor stem cells: molecular characteristics and their impact on therapy. Mol Asp Med. 2014;39:82-101.

48. Iyer AK, Singh A, Ganta S, Amiji MM. Role of integrated cancer nanomedicine in overcoming drug resistance. Adv Drug Deliv Rev. 2013;65:1784-802.

49. Ling S, Shan Q, Zhan Q, Ye Q, Liu P, Xu S, et al. USP22 promotes hypoxiainduced hepatocellular carcinoma stemness by a HIF1a/USP22 positive feedback loop upon TP53 inactivation. Gut. 2019;69:1322-1334.

50. Ju S, Wang F, Wang Y, Ju S. CSN8 is a key regulator in hypoxia-induced epithelial-mesenchymal transition and dormancy of colorectal cancer cells. Mol Cancer. 2020;19:168.

51. Lan J, Lu H, Samanta D, Salman S, Lu Y, Semenza GL. Hypoxia-inducible factor 1-dependent expression of adenosine receptor 2B promotes breast cancer stem cell enrichment. Proc Natl Acad Sci USA. 2018;115:E9640-E8.

52. Cao J, Li J, Sun L, Qin T, Xiao Y, Chen K, et al. Hypoxia-driven paracrine osteopontin/integrin av $\beta 3$ signaling promotes pancreatic cancer cell epithelialmesenchymal transition and cancer stem cell-like properties by modulating forkhead box protein M1. Mol Oncol. 2019;13:228-45.

53. Ullmann P, Nurmik M, Schmitz M, Rodriguez F, Weiler J, Qureshi-Baig K, et al. Tumor suppressor miR-215 counteracts hypoxia-induced colon cancer stem cell activity. Cancer Lett. 2019;450:32-41.

54. Almiron Bonnin DA, Havrda MC, Lee MC, Liu H, Zhang Z, Nguyen LN, et al. Secretion-mediated STAT3 activation promotes self-renewal of glioma stem-like cells during hypoxia. Oncogene. 2018;37:1107-18.
55. Brooks DL, Schwab LP, Krutilina R, Parke DN, Sethuraman A, Hoogewijs D, et al. ITGA6 is directly regulated by hypoxia-inducible factors and enriches for cancer stem cell activity and invasion in metastatic breast cancer models. Mol Cancer. 2016;15:26.

56. Wang Y, Zhang T, Guo L, Ren T, Yang Y. Stromal extracellular matrix is a microenvironmental cue promoting resistance to EGFR tyrosine kinase inhibitors in lung cancer cells. Int J Biochem Cell Biol. 2019;106:96-106.

57. Azzariti A, Mancarella S, Porcelli L, Quatrale AE, Caligiuri A, Lupo L, et al. Hepatic stellate cells induce hepatocellular carcinoma cell resistance to sorafenib through the laminin-332/a3 integrin axis recovery of focal adhesion kinase ubiquitination. Hepatology 2016;64:2103-17.

58. Rohn F, Kordes C, Castoldi M, Götze S, Poschmann G, Stühler K, et al. Laminin521 promotes quiescence in isolated stellate cells from rat liver. Biomaterials. 2018;180:36-51.

59. Govaere O, Wouters J, Petz M, Vandewynckel YP, Van den Eynde K, Van den Broeck A, et al. Laminin-332 sustains chemoresistance and quiescence as part of the human hepatic cancer stem cell niche. J Hepatol. 2016;64:609-17.

60. LeBleu VS, Kalluri R. A peek into cancer-associated fibroblasts: origins, functions and translational impact. Dis Models Mechan. 2018;11:dmm029447.

61. Kalluri R, Zeisberg M. Fibroblasts in cancer. Nat Rev Cancer. 2006;6:392-401.

62. Su S, Chen J, Yao H, Liu J, Yu S, Lao L, et al. CD10GPR77 cancer-associated fibroblasts promote cancer formation and chemoresistance by sustaining cancer stemness. Cell 2018;172:841-56.

63. Liu C, Liu L, Chen X, Cheng J, Zhang H, Zhang C, et al. LSD1 stimulates cancerassociated fibroblasts to drive notch3-dependent self-renewal of liver cancer stem-like cells. Cancer Res. 2018:78:938-49.

64. Chen J-H, Wu A, Bamodu OA, Yadav VK, Chao TY, Tzeng YM, et al. Ovatodiolide suppresses oral cancer malignancy by down-regulating exosomal mir-21/stat3/ $\beta$-catenin cargo and preventing oncogenic transformation of normal gingival fibroblasts. Cancers. 2019;12:56.

65. Vaquero J, Lobe C, Tahraoui S, Clapéron A, Mergey M, Merabtene F, et al. The IGF2/IR/IGF1R pathway in tumor cells and myofibroblasts mediates resistance to EGFR inhibition in cholangiocarcinoma. Clin Cancer Res. 2018:24:4282-96.

66. Ren J, Ding L, Zhang D, Shi G, Xu Q, Shen S, et al. Carcinoma-associated fibroblasts promote the stemness and chemoresistance of colorectal cancer by transferring exosomal IncRNA H19. Theranostics. 2018;8:3932-48.

67. Wang T, Wang D, Zhang L, Yang P, Wang J, Liu Q, et al. The TGF $3-m i R-499 a-$ SHKBP1 pathway induces resistance to EGFR inhibitors in osteosarcoma cancer stem cell-like cells. J Exp Clin Cancer Res. 2019;38:226.

68. Wells RG. The role of matrix stiffness in regulating cell behavior. Hepatology. 2008;47:1394-400.

69. Liu Y, Lv J, Liang X, Yin X, Zhang L, Chen D, et al. Fibrin stiffness mediates dormancy of tumor-repopulating cells via a Cdc42-driven Tet2 epigenetic program. Cancer Res. 2018;78:3926-37.

70. Shin JW, Mooney DJ. Extracellular matrix stiffness causes systematic variations in proliferation and chemosensitivity in myeloid leukemias. Proc Natl Acad Sci USA. 2016;113:12126-31.

71. Zhao J. Cancer stem cells and chemoresistance: the smartest survives the raid. Pharmacol Therapeutics. 2016;160:145-58.

72. Hayes JD, Dinkova-Kostova AT, Tew KD. Oxidative stress in cancer. Cancer Cell. 2020;38:167-97.

73. Wang Y-P, Zhou LS, Zhao YZ, Wang SW, Chen LL, Liu LX, et al. Regulation of G6PD acetylation by SIRT2 and KAT9 modulates NADPH homeostasis and cell survival during oxidative stress. EMBO J. 2014;33:1304-20.

74. Anderson AS, Roberts PC, Frisard MI, Hulver MW, Schmelz EM. Ovarian tumorinitiating cells display a flexible metabolism. Exp Cell Res. 2014;328:44-57.

75. Kim JH, Lee KJ, Seo Y, Kwon JH, Yoon JP, Kang JY, et al. Effects of metformin on colorectal cancer stem cells depend on alterations in glutamine metabolism. Sci Rep. 2018;8:409.

76. Luo M, Shang L, Brooks MD, Jiagge E, Zhu Y, Buschhaus JM, et al. Targeting breast cancer stem cell state equilibrium through modulation of redox signaling. Cell Metab. 2018;28:69-86.

77. Fan J, Ye J, Kamphorst JJ, Shlomi T, Thompson CB, Rabinowitz JD. Quantitative flux analysis reveals folate-dependent NADPH production. Nature. 2014;510:298-302.

78. Chandimali N, Jeong DK, Kwon T. Peroxiredoxin II regulates cancer stem cells and stemness-associated properties of cancers. Cancers. 2018;10:305.

79. Jagust $P$, Alcalá S Jr, Sainz B, Heeschen C, Sancho P. Glutathione metabolism is essential for self-renewal and chemoresistance of pancreatic cancer stem cells. World J Stem Cells. 2020;12:1410-28.

80. Lee H-J, Li CF, Ruan D, He J, Montal ED, Lorenz S, et al. Non-proteolytic ubiquitination of Hexokinase 2 by HectH9 controls tumor metabolism and cancer stem cell expansion. Nat Commun. 2019;10:2625.

81. Sancho $P$, Barneda D, Heeschen C. Hallmarks of cancer stem cell metabolism. $\mathrm{Br}$ J Cancer. 2016;114:1305-12. 
82. Deshmukh A, Deshpande K, Arfuso F, Newsholme P, Dharmarajan A. Cancer stem cell metabolism: a potential target for cancer therapy. Mol Cancer. 2016;15:69.

83. Feng W, Gentles A, Nair RV, Huang M, Lin $Y$, Lee $C Y$, et al. Targeting unique metabolic properties of breast tumor initiating cells. Stem Cells. 2014;32:1734-45.

84. Diehn M, Cho RW, Lobo NA, Kalisky T, Dorie MJ, Kulp AN, et al. Association of reactive oxygen species levels and radioresistance in cancer stem cells. Nature. 2009;458:780-3.

85. Kim YS, Kang MJ, Cho YM. Low production of reactive oxygen species and high DNA repair: mechanism of radioresistance of prostate cancer stem cells. Anticancer Res. 2013;33:4469-74.

86. Dai J, Ji Y, Wang W, Kim D, Fai LY, Wang L, et al. Loss of fructose-1,6-bisphosphatase induces glycolysis and promotes apoptosis resistance of cancer stemlike cells: an important role in hexavalent chromium-induced carcinogenesis. Toxicol Appl Pharm. 2017;331:164-73.

87. Zhang K, Xu P, Sowers JL, Machuca DF, Mirfattah B, Herring J, et al. Proteome analysis of hypoxic glioblastoma cells reveals sequential metabolic adaptation of one-carbon metabolic pathways. Mol Cell Proteom. 2017;16:1906-21.

88. Zhao H, Duan Q, Zhang Z, Li H, Wu H, Shen Q, et al. Up-regulation of glycolysis promotes the stemness and EMT phenotypes in gemcitabine-resistant pancreatic cancer cells. J Cell Mol Med. 2017;21:2055-67.

89. Deshmukh A, Arfuso F, Newsholme P, Dharmarajan A. Regulation of cancer stem cell metabolism by secreted frizzled-related protein 4 (sFRP4). Cancers. 2018;10:40.

90. Lo Re O, Douet J, Buschbeck M, Fusilli C, Pazienza V, Panebianco C, et al. Histone variant macroH2A1 rewires carbohydrate and lipid metabolism of hepatocellular carcinoma cells towards cancer stem cells. Epigenetics. 2018;13:829-45.

91. Yan B, Jiang Z, Cheng L, Chen K, Zhou C, Sun L, et al. Paracrine HGF/c-MET enhances the stem cell-like potential and glycolysis of pancreatic cancer cells via activation of YAP/HIF-1a. Exp Cell Res. 2018;371:63-71.

92. O'Neill S, Porter RK, McNamee N, Martinez VG, O'Driscoll L. 2-Deoxy-D-Glucose inhibits aggressive triple-negative breast cancer cells by targeting glycolysis and the cancer stem cell phenotype. Sci Rep. 2019;9:3788.

93. Vlashi E, Lagadec C, Vergnes L, Matsutani T, Masui K, Poulou M, et al. Metabolic state of glioma stem cells and nontumorigenic cells. Proc Natl Acad Sci USA. 2011;108:16062-7.

94. Janiszewska M, Suvà ML, Riggi N, Houtkooper RH, Auwerx J, Clément-Schatlo V et al. Imp2 controls oxidative phosphorylation and is crucial for preserving glioblastoma cancer stem cells. Genes Dev. 2012;26:1926-44.

95. Lin S, Huang C, Sun J, Bollt O, Wang X, Martine E, et al. The mitochondrial deoxyguanosine kinase is required for cancer cell stemness in lung adenocarcinoma. EMBO Mol Med. 2019;11:e10849.

96. Sancho $P$, Burgos-Ramos $E$, Tavera A, Bou Kheir T, Jagust $P$, Schoenhals $M$, et al. MYC/PGC-1a balance determines the metabolic phenotype and plasticity of pancreatic cancer stem cells. Cell Metab. 2015;22:590-605.

97. Vlashi E, Kim K, Lagadec C, Donna LD, McDonald JT, Eghbali M, et al. In vivo imaging, tracking, and targeting of cancer stem cells. J Natl Cancer Inst. 2009;101:350-9.

98. Dong C, Yuan T, Wu Y, Wang Y, Fan TW, Miriyala S, et al. Loss of FBP1 by snailmediated repression provides metabolic advantages in basal-like breast cancer. Cancer Cell. 2013:23:316-31.

99. Liao J, Liu PP, Hou G, Shao J, Yang J, Liu K, et al. Regulation of stem-like cancer cells by glutamine through beta-catenin pathway mediated by redox signaling. Mol Cancer. 2017;16:51.

100. Li B, Cao Y, Meng G, Qian L, Xu T, Yan C, et al. Targeting glutaminase attenuates stemness properties in hepatocellular carcinoma by increasing reactive oxygen species and suppressing $\mathrm{Wnt} /$ beta-catenin pathway. EBioMedicine. 2019;39:239-54

101. Kamarajan P, Rajendiran TM, Kinchen J, Bermúdez M, Danciu T, Kapila YL. Head and neck squamous cell carcinoma metabolism draws on glutaminolysis, and stemness is specifically regulated by glutaminolysis via aldehyde dehydrogenase. J Proteome Res. 2017:16:1315-26.

102. Fujita S, Honma D, Adachi N, Araki K, Takamatsu E, Katsumoto T, et al. Dual inhibition of EZH1/2 breaks the quiescence of leukemia stem cells in acute myeloid leukemia. Leukemia. 2018;32:855-64.

103. Jiang YX, Yang SW, Li PA, Luo X, Li ZY, Hao YX, et al. The promotion of the transformation of quiescent gastric cancer stem cells by IL-17 and the underlying mechanisms. Oncogene. 2017;36:1256-64.

104. Li H, Zhao N, Li Y, Xing H, Chen S, Xu Y, et al. c-MPL is a candidate surface marker and confers self-renewal, quiescence, chemotherapy resistance, and leukemia initiation potential in leukemia stem cells. Stem Cells. 2018;36:1685-96.

105. Liu P, Kumar IS, Brown S, Kannappan V, Tawari PE, Tang JZ, et al. Disulfiram targets cancer stem-like cells and reverses resistance and cross-resistance in acquired paclitaxel-resistant triple-negative breast cancer cells. $\mathrm{Br} \mathrm{J}$ Cancer. 2013:109:1876-85.
106. Sadarangani A, Pineda G, Lennon KM, Chun HJ, Shih A, Schairer AE, et al. GLI2 inhibition abrogates human leukemia stem cell dormancy. J Transl Med. 2015;13:98.

107. Baquero P, Dawson A, Mukhopadhyay A, Kuntz EM, Mitchell R, Olivares O, et al. Targeting quiescent leukemic stem cells using second generation autophagy inhibitors. Leukemia. 2019;33:981-94.

108. Chesnelong C, Hao X, Cseh O, Wang AY, Luchman HA, Weiss S. SLUG directs the precursor state of human brain tumor stem cells. Cancers. 2019;11:1635.

109. Haraguchi $N$, Ishii $H$, Mimori K, Tanaka F, Ohkuma M, Kim HM, et al. CD13 is a therapeutic target in human liver cancer stem cells. J Clin Invest. 2010;120:3326-39.

110. Jin Y, Nie D, Li J, Du X, Lu Y, Li Y, et al. Gas6/AXL signaling regulates self-renewal of chronic myelogenous leukemia stem cells by stabilizing $\beta$-catenin. Clin Cancer Res. 2017:23:2842-55.

111. Moro M, Bertolini G, Pastorino U, Roz L, Sozzi G. Combination treatment with alltrans retinoic acid prevents cisplatin-induced enrichment of CD133+ tumorinitiating cells and reveals heterogeneity of cancer stem cell compartment in lung cancer. J Thorac Oncol. 2015;10:1027-36.

112. Neviani P, Harb JG, Oaks JJ, Santhanam R, Walker CJ, Ellis JJ, et al. PP2Aactivating drugs selectively eradicate TKI-resistant chronic myeloid leukemic stem cells. J Clin Invest. 2013;123:4144-57.

113. Adomako A, Calvo V, Biran N, Osman K, Chari A, Paton JC, et al. Identification of markers that functionally define a quiescent multiple myeloma cell subpopulation surviving bortezomib treatment. BMC Cancer. 2015;15:444.

114. El Touny LH, Vieira A, Mendoza A, Khanna C, Hoenerhoff MJ, Green JE. Combined SFK/MEK inhibition prevents metastatic outgrowth of dormant tumor cells. J Clin Invest. 2014;124:156-68.

115. Marshall JC, Collins JW, Nakayama J, Horak CE, Liewehr DJ, Steinberg SM, et al. Effect of inhibition of the lysophosphatidic acid receptor 1 on metastasis and metastatic dormancy in breast cancer. J Natl Cancer Inst. 2012;104:1306-19.

116. Sosa MS, Parikh F, Maia AG, Estrada Y, Bosch A, Bragado P, et al. NR2F1 controls tumour cell dormancy via SOX9- and RARß-driven quiescence programmes. Nat Commun. 2015;6:6170.

117. Nowak D, Stewart D, Koeffler HP. Differentiation therapy of leukemia: 3 decades of development. Blood. 2009;113:3655-65.

118. Stahl M, Kohrman N, Gore SD, Kim TK, Zeidan AM, Prebet T. Epigenetics in cancer: a hematological perspective. PLoS Genet. 2016;12:e1006193-e.

119. Feng $X$, Shi $Y$, Xie L, Zhang $K$, Wang $X$, Liu $Q$, et al. 2-deoxy-D-glucose augments photodynamic therapy induced mitochondrial caspase-independent apoptosis and energy-mediated autophagy. Lasers Surg Med. 2019;51:352-62.

120. Oladghaffari $M$, Islamian JP, Baradaran B, Monfared AS, Farajollahi A, Shanehbandi $D$, et al. High efficiency apoptosis induction in breast cancer cell lines by MLN4924/2DG co-treatment. Asian Pac J Cancer Prev. 2015;16:5471-6.

121. Zhang L, Su J, Xie Q, Zeng L, Wang Y, Yi D, et al. 2-Deoxy-d-glucose sensitizes human ovarian cancer cells to cisplatin by increasing ER stress and decreasing ATP stores in acidic vesicles. J Biochem Mol Toxicol. 2015;29:572-8.

122. Gale M, Li Y, Cao J, Liu ZZ, Holmbeck MA, Zhang M, et al. Acquired resistance to HER2-targeted therapies creates vulnerability to ATP synthase inhibition. Cancer Res. 2020;80:524-35.

123. Matassa DS, Amoroso MR, Lu H, Avolio R, Arzeni D, Procaccini $C$, et al. Oxidative metabolism drives inflammation-induced platinum resistance in human ovarian cancer. Cell Death Differ. 2016:23:1542-54.

124. Cruz-Bermúdez A, Laza-Briviesca R, Vicente-Blanco RJ, García-Grande A, Coronado MJ, Laine-Menéndez $\mathrm{S}$, et al. Cisplatin resistance involves a metabolic reprogramming through ROS and PGC-1a in NSCLC which can be overcome by OXPHOS inhibition. Free Radic Biol Med. 2019;135:167-81.

125. Yang Z, Guo F, Albers AE, Sehouli J, Kaufmann AM. Disulfiram modulates ROS accumulation and overcomes synergistically cisplatin resistance in breast cancer cell lines. Biomed Pharmacother. 2019;113:108727.

126. Sherman MH, Yu RT, Engle DD, Ding N, Atkins AR, Tiriac $H$, et al. Vitamin D receptor-mediated stromal reprogramming suppresses pancreatitis and enhances pancreatic cancer therapy. Cell. 2014;159:80-93.

127. Carapuça EF, Gemenetzidis E, Feig C, Bapiro TE, Williams MD, Wilson AS, et al. Anti-stromal treatment together with chemotherapy targets multiple signalling pathways in pancreatic adenocarcinoma. J Pathol. 2016;239:286-96.

128. de Sousae Melo F, Kurtova AV, Harnoss JM, Kljavin N, Hoeck JD, Hung J, et al. A distinct role for Lgr5 stem cells in primary and metastatic colon cancer. Nature. 2017;543:676-80.

\section{ACKNOWLEDGEMENTS}

This work was supported by the National Natural Science Funds for Distinguished Young Scholars of China [Grant number: 81625003], Natural Science Foundation of Zhejiang Province (Zhejiang Provincial Natural Science Foundation) [Grant number: 2019C03050], and the National Natural Science Foundation of China [Grant number: 81902407]. 
12

\section{AUTHOR CONTRIBUTIONS}

XX, JW and KC jointly designed the theme and content structure. KC and CZ wrote the manuscript. SL conducted the editing and critical revision. RW drew the figures. All the co-authors have read and approved the final manuscript for publication.

\section{COMPETING INTERESTS}

The authors declare no competing interests.

\section{ADDITIONAL INFORMATION}

Correspondence and requests for materials should be addressed to Xiao Xu.

Reprints and permission information is available at http://www.nature.com/ reprints

Publisher's note Springer Nature remains neutral with regard to jurisdictional claims in published maps and institutional affiliations.

(c) (i) Open Access This article is licensed under a Creative Commons Attribution 4.0 International License, which permits use, sharing, adaptation, distribution and reproduction in any medium or format, as long as you give appropriate credit to the original author(s) and the source, provide a link to the Creative Commons license, and indicate if changes were made. The images or other third party material in this article are included in the article's Creative Commons license, unless indicated otherwise in a credit line to the material. If material is not included in the article's Creative Commons license and your intended use is not permitted by statutory regulation or exceeds the permitted use, you will need to obtain permission directly from the copyright holder. To view a copy of this license, visit http://creativecommons. org/licenses/by/4.0/.

(c) The Author(s) 2021 